\title{
Characterization of Virginia Tobaccos by Chemometric Methods*
}

\author{
by \\ E. Apostolova ${ }^{1}$, S. Dagnon ${ }^{1}$, A. Edreva ${ }^{2}$ \\ ${ }^{1}$ Institute of Tobacco and Tobacco Products, 4108 Plovdiv, Bulgaria \\ ${ }^{2}$ D. Kostoff Institute of Genetics, Bulgarian Academy of Sciences, 1113 Sofia, Bulgaria
}

\section{SUMMARY}

Leaf samples of different flue-cured Virginia tobacco varieties were analyzed and compared to a standard, the typical American Virginia cultivar K 326. Plants were grown in the Plovdiv region, Bulgaria, under conditions appropriate for Virginia varieties. The tobaccos were characterized by means of high performance liquid chromatography (HPLC) of polyphenols and capillary gas chromatography (CGC) of the neutral volatiles of essential oils, as well as by a sensory evaluation of color and aroma. All cultivars examined contained twelve polyphenol components in their HPLC profiles and differed only in quantitative aspects. Both qualitative and quantitative variations between the CGC profiles of essential oils of the cultivars were observed. The chromatographic profiles of polyphenols and essential oils were compared by the pattern recognition method (PRM) and used for calculating the similarity indexes $\left(I_{\mathrm{s}}, \%\right)$ of the samples to the standard Virginia variety K 326 . The chemometric data obtained are completely compatible with sensory evaluation of color and aroma. Based on the results obtained the tobaccos may be distinguished as: typical full-flavored Virginia - aromatic (Virginia 330); typical full-flavored Virginia - less aromatic (Virginia 0454); non-typical (filler type) Virginia (Virginia 42). The possibilities of the PRM for objective evaluation of color and aroma of Virginia tobaccos were demonstrated. [Beitr. Tabakforsch. Int. 20 (2002) 1-6]

\section{ZUSAMMENFASSUNG}

Die Blätter verschiedener flue-cured Virginiatabake wurden analysiert und mit einem Standardtabak verglichen, der typischen amerikanischen Virginia-Zuchtsorte K 326. Die Pflanzen wurden in der Region Plovdiv in Bulgarien unter für Virginia-Varietäten geeigneten Bedingungen kultiviert. Die Tabakvarietäten wurden mittels Hochleistungsflüssigkeitschromatographie (HPLC) zur Bestimmung der Polyphenole und Kapillar-Gaschromatographie (CGC) zur Bestimmung der neutralen flüchtigen ätherischen Öle als auch durch sensorische Evaluation der Farbe und des Aromas analysiert. Alle untersuchten Zuchtsorten wiesen in ihren HPLC-Profilen zwölf Polyphenolverbindungen auf und unterschieden sich nur in quantitativer Hinsicht. Zwischen den Zuchtsorten wurden sowohl qualitative als auch quantitative Unterschiede bei den CGC-Profilen der ätherischen Öle beobachtet. Die Chromatographieprofile der Polyphenole und ätherischen Öle wurden mit Hilfe der Struktur-Erkennungsmethode (PRM = Pattern Recognition Method) verglichen und Ähnlichkeitsindizes $\left(I_{\mathrm{s}}, \%\right)$ der Proben zur Standard-Virginiavarietät K 326 berechnet. Die chemometrischen Daten sind mit der sensorischen Beurteilung der Farbe und des Aromas vollständig kompatibel. Auf der Basis der Ergebnisse können die Tabake folgendermaßen unterschieden werden: typischer aromatischer full-flavour Virginia (Virginia 330), typischer weniger aromatischer full-flavour Virginia (Virginia 0454); untypischer (Typ Fülltabak) Virginia (Virginia 42). Die Möglichkeiten der PRM zur objektiven Beurteilung der Farbe und des Aromas von Virginiatabaken werden aufgezeigt. [Beitr. Tabakforsch. Int. 20 (2002) 1-6]

\section{RESUME}

Des échantillons de différentes variétés de tabac de type Virginie ont été analysés et comparés avec un tabac standard, la variété Virginie américaine K 326. Les plantes ont été cultivées dans la région de Plovdiv, Bulgarie, dans des conditions appropriées. Les tabacs ont été caractérisés par chromatographie liquide à haute performance (HPLC) pour doser les substances polyphénoliques et par chromato- 
graphie en phase gazeuse sur colonne capillaire (CGC) pour doser les substances volatiles neutres des huiles essentielles, de même que par une évaluation sensorielle de la couleur et de l'arôme. Tous les cultivars examinés ont présenté douze composés polyphénoliques dans leurs profils HPLC et ont uniquement différé quantitativement. Des variations qualitatives et quantitatives entre les profils CGC des huiles essentielles des différents cultivars ont été observées. Les profils chromatographiques des polyphénols et des huiles essentielles ont été comparés au moyen de la méthode de reconnaissance des patrons (PRM) et ont servi à calculer les index de similitude $\left(I_{s}, \%\right)$ des échantillons par rapport à la variété standard Virginie K 326. Les données chimiométriques sont totalement en accord avec les résultats obtenus par l'évaluation sensorielle de la couleur et de l'arôme. A partir des résultats obtenus, les catégories suivantes ont pu être établies: Virginie typique plein arôme - aromatique (Virginia 330), Virginie typique plein arôme - moins aromatique (Virginia 0454), Virginie non typique (de type remplissage) (Virginia 42). Les possibilités de la méthode de reconnaissance des patrons en vue d'une évaluation objective de la couleur et de l'arôme des tabacs Virginie sont présentées. [Beitr. Tabakforsch. Int. 20 (2002) 1-6]

\section{INTRODUCTION}

For quality evaluation of natural products organoleptic methods are routinely used. Their subjective character however necessitates supplementation with objective methods, particularly chromatography, providing valuable multi-component information for quality parameters. However, visual analysis of chromatograms is difficult and not reliable especially when comparing a large number of specimens. The problem was overcome through the development of chemometric methods applying mathematical processing of chromatographic profiles (15). Chemometrics, including pattern recognition methods (PRM) has been introduced for estimation of a range of quality characters, such as aroma, taste, flavor, etc., and is applied in the practice for quality assessment of essential oils, olive oils, fruits, wine $(3,6,7,16,17)$, as well as for medical diagnostics (10). Few data (12) however (dealing exclusively with aroma but not with color) are available on application of PRM in tobacco. Color and aroma are major characters important for tobacco quality which are related to the polyphenol and essential oil constituents, respectively $(8,9,13,14,19)$. Taking this into account, the aim of the present work was to perform color and aroma characterization and ranking of Virginia tobaccos by using PRM based on high performance liquid chromatography (HPLC) profiles of polyphenols and capillary gas chromatography (CGC) profiles of essential oils. In our study the neutral volatile fraction of essential oils extracted from the sample was used for CGC in contrast to the majority of PRM aroma assessments based on headspace vapor CGC profiles $(11,12)$. In this way some of the inconveniences of the headspace sampling could be obviated, such as insufficient reproducibility, poor chromatographic profiles, or requirements of special additional experimental devices for profile enrichment and improved reproducibility.

\section{EXPERIMENTAL}

\section{Material}

Flue-cured Virginia tobacco varieties Virginia 330, Virginia 0454, and Virginia 42 bred in the Institute of Tobacco and Tobacco Products (ITTP), Plovdiv, Bulgaria, were used as a material. They were released in terms of a breeding program aiming at developing new flavor and filler type Virginia tobacco varieties appropriate for the soil and climatic conditions of the country. All varieties were obtained by intervarietal hybridisation of Virginia tobaccos and are of fertile type $(4,22)$. The genitors of Virginia 0454 are Coker 347 (maternal parent) and the breeding line 825 (male parent) (4). The cultivar Virginia 330 results from a cross between Speight G-58 (female) and Virginia 890 (male) (22). The cultivars Virginia 8 (female) and Virginia 385 (male) are genitors of Virginia 42 (STOYANOV, personal communication). The American flue-cured Virginia variety K 326 was also involved in the study, being used as a standard. K 326, having excellent grade index values, was the most popular flue-cured variety in all belts in North Carolina since 1984 (18).The plants were grown in the experimental field of ITTP-Plovdiv under agrotechnical conditions appropriate for Virginia tobaccos. The randomized block scheme (in 4 replicates) was applied. The density was 190 plants per plot. Leaves without midribs taken from the middle stalk position were analyzed.

\section{HPLC of polyphenols}

The leaf material was extracted with $\mathrm{CH}_{3} \mathrm{OH}: \mathrm{H}_{2} \mathrm{O}(60: 40$, $v / v)$. Fractionation of the extract was done with cartridge C18 according to COURT (5). Polyphenols were determined by using the reversed phase HPLC method $(20,21)$. Chromatography was carried out at the following conditions allowing maximum separation of chlorogenic acid from its isomer 4-0-caffeoyl quinic acid, namely: liquid chromatograph Perkin Elmer (Perkin Elmer Ltd., Beaconsfield, Buckinghamshire, England) equipped with LC 290 binary pump, LC290 UV/VIS detector and LCI-100 integrator; analytical column Kromasil LC18, 150 mm, 5 m , 4.6 mm i.d. (Supelco Park, Bellefonte, PA, USA); single wavelength at $340 \mathrm{~nm}$; eluent flow rate $1.0 \mathrm{~mL} / \mathrm{min}^{-1}$; sample volume $20 \mu \mathrm{L}$; solvent composition $\mathrm{A}=\mathrm{CH}_{3} \mathrm{OH}: \mathrm{H}_{2} \mathrm{O}$ : $\mathrm{CH}_{3} \mathrm{COOH} \quad(5: 93: 2) ; \quad \mathrm{B}=\mathrm{CH}_{3} \mathrm{OH}: \mathrm{H}_{2} \mathrm{O}: \mathrm{CH}_{3} \mathrm{COOH}$ (86:12:2). Gradient elution profile was $100 \% \mathrm{~A}, 0 \mathrm{~min} ; 20$ min to $85 \% \mathrm{~A} ; 5$ min to $80 \% \mathrm{~A} ; 17 \mathrm{~min}$ to $45 \% \mathrm{~A} ; 5 \mathrm{~min}$ to $100 \%$ A or $5 \mathrm{~min}$ to $0 \%$ A for cleaning.

The reproducibility of the method is good with a typical standard deviation of about $2 \%$ for chlorogenic acid, scopoletin and rutin. Peaks of chlorogenic acid, scopoletin and rutin were identified by using reference compounds. Peak assignments for those components where no references were available (neochlorogenic and 4-0-caffeoyl quinic acid) were based on data for retention time according to SNOOK and CHORTYK (20).

\section{CGC of essential oils}

The neutral steam volatiles of essential oils were analyzed according to the procedure of WU et al. (23). The 
Table 1. Color and aroma estimation of Virginia tobaccos by expert evaluation and smoking panel assessment. Data are means from five replicates. Standard deviations are less than $10 \%$ of the means. Values are significantly different at $P \leq 5 \%$ (Student's $t$ - test)

\begin{tabular}{|c|c|c|c|c|}
\hline \multirow[b]{2}{*}{ Cultivars } & \multicolumn{2}{|l|}{ Color } & \multicolumn{2}{|c|}{ Aroma } \\
\hline & Expert evaluation & Score & Smoking panel assessment & Total score \\
\hline K 326 & Orange to orange-red & 16.2 & $\begin{array}{l}\text { Intensity (2.5) } \\
\text { Pleasantness (6.3) } \\
\text { Purity (3.0) } \\
\text { Typicalness (4.0) } \\
\text { Density }(2.8)\end{array}$ & 18.6 \\
\hline Virginia 330 & Orange & 15.0 & $\begin{array}{l}\text { Intensity (3.0) } \\
\text { Pleasantness (5.9) } \\
\text { Purity (2.3) } \\
\text { Typicalness (3.2) } \\
\text { Density (2.2) }\end{array}$ & 16.6 \\
\hline Virginia 0454 & Yellow-orange to orange & 13.7 & $\begin{array}{l}\text { Intensity (2.8) } \\
\text { Pleasantness (5.5) } \\
\text { Purity }(2.6) \\
\text { Typicalness }(2.7) \\
\text { Density (2.8) }\end{array}$ & 16.4 \\
\hline Virginia 42 & Yellow & 10.0 & $\begin{array}{l}\text { Intensity (3.2) } \\
\text { Pleasantness (5.0) } \\
\text { Purity (1.0) } \\
\text { Typicalness (1.0) } \\
\text { Density (4.0) }\end{array}$ & 14.2 \\
\hline
\end{tabular}

following experimental procedure was used. Leaf sample $(25 \mathrm{~g})$ of ground dry tobacco was suspended in $500 \mathrm{~mL} 2 \%$ $\mathrm{H}_{2} \mathrm{SO}_{4}$ in water $(w / v)$ and distilled using the British Pharmacopoeia apparatus. The obtained essential oils were extracted with methylene chloride. The extract containing the neutral volatiles was used for CGC. The chromatography was carried out by using a gas chomatograph Perkin Elmer 8700 (Perkin Elmer Ltd., Beaconsfield, Buckinghamshire, England), equipped with a flame ionisation detector. An analytical column SPB-5 (Supelco Park, Bellefonte, PA, USA), length $30 \mathrm{~m} \times 0.32 \mathrm{~mm}$ i.d. and 0.3 $\mu \mathrm{m}$ film thickness was used. Conditions ensuring good reproducibility were as follows: detector temperature $280{ }^{\circ} \mathrm{C}$, injector $260^{\circ} \mathrm{C}$, split $1: 30$; carrier gas $\mathrm{H}_{2}$ at 9 psi. The column oven was temperature programmed from $80^{\circ} \mathrm{C}$ (0 min) to $250{ }^{\circ} \mathrm{C}$ (held for $1 \mathrm{~min}$ ) at $5{ }^{\circ} \mathrm{C}$ per min. Both HPLC and CGC analyses were done in triplicate. The average value of the three analyses was used in the PRM.

\section{Pattern recognition methods}

PRM was performed according to the Package software program "Patreco" (Pharmaceutical Institute, Sofia, Bulgaria) (6). Processing of HPLC profiles was done using all 12 peaks present in each sample. CGC profiles were processed on the basis of 51 peaks, having statistically significant height, selected from the samples studied. The matrix for PRM was designed using the retention time of the peaks and the percent ratio of the height of each peak to the sum of the heights of all selected peaks. PRM data are presented as indexes of similarity $\left(I_{\mathrm{s}}, \%\right)(6) . I_{\mathrm{s}}$ of $97 \%$ are considered as a limit value. Above this value differences are not significant.

\section{Sensory evaluation}

Color was assayed according to a scale encompassing five basic and intermediary colors: yellow, red, orange, yellow- orange and orange-red (2). Data are also presented as scores using numerical values for the different colors. Basic colors are expressed as follows: yellow $=10$, red $=$ 20 , orange $=15$. Intermediary colors are expressed as arithmetical means of basic colors, namely: orange to orange-red $[15+(15+20) / 2] / 2=16.2$; yellow-orange to orange $[15+(10+15) / 2] / 2=13.7$. Aroma was evaluated by assessment of five attributes of smoke (intensity, pleasantness, purity, typicalness, density) on a ten point scale. The total score is a sum of the scores of these attributes (1). The color and aroma evaluation was done by panels consisting of five experts. Values are significantly different at $P \leq 5 \%$ (Student's $t$ test).

\section{RESULTS}

\section{Sensory color and aroma evaluation}

The sensory assessment of color and aroma of tobaccos studied is presented in Table 1 and Figure 3. Differences in the color pattern of the cultivars varied from 10.0 for Virginia 42 to 16.2 for K 326 . Scores of aroma assessment varied from 14.2 for Virginia 42 to 18.6 for K 326 . The high quality scores of K 326 grown in conditions of Plovdiv, Bulgaria, suggest that it can be regarded as a fullflavored Virginia tobacco, and allow its use as a standard in PRM processing of HPLC and CGC profiles.

\section{HPLC profiles of polyphenols}

All cultivars studied contained 12 well expressed peaks. Components 1, 4 and 5 were identified as neochlorogenic (5-0-caffeoylquinic), chlorogenic (3-0-caffeoylquinic) and 4-0-caffeoylquinic acids, respectively, peak 8 as scopoletin and peak 10 as rutin. Chlorogenic acid and its isomers, as 


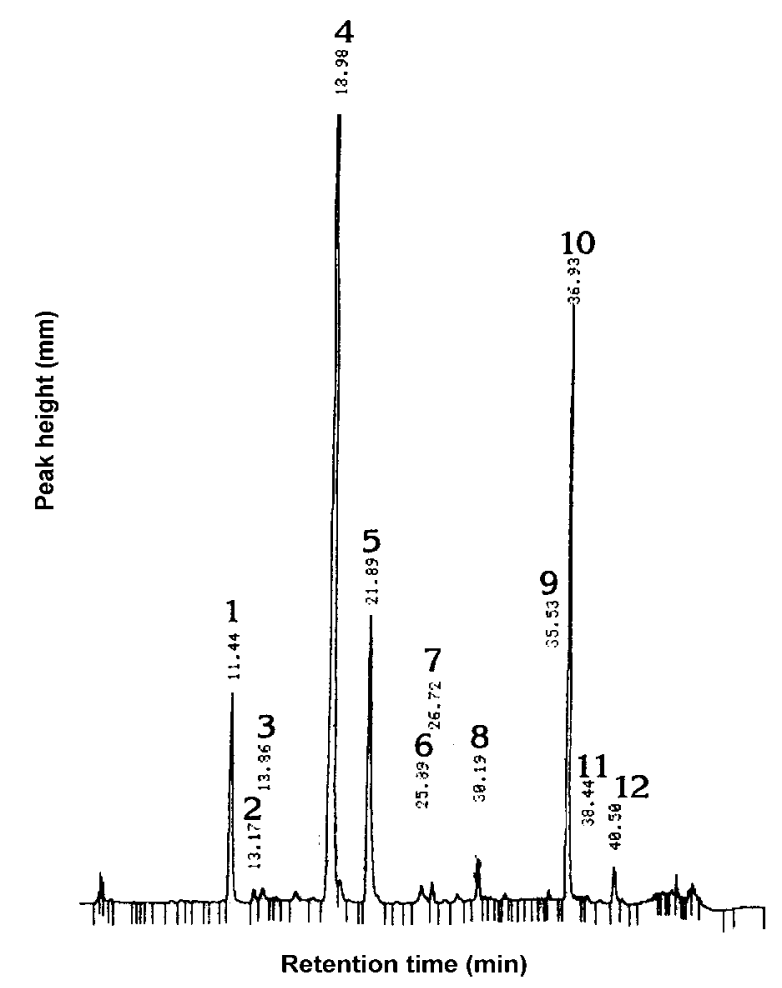

Figure 1. HPLC profile of polyphenols in Virginia variety $\mathrm{K}$ 326; components 1, 4, 5 are identified as neochlorogenic (5-0caffeoylquinic), chlorogenic (3-0-caffeoylquinic) and 4-0caffeoylquinic acids, respectively, component 8 as scopoletin, and component 10 as rutin

well as rutin were the major polyphenol components. Only quantitative differences in the polyphenol pattern of the cultivars were observed. An example of a HPLC profile of polyphenols of the standard Virginia variety K 326 is given in Figure 1.

\section{CGC profiles of neutral volatiles of essential oils}

A total of 86 peaks was surveyed in the chromatograms of the Virginia tobaccos. The CGC pattern of the standard Virginia variety K 326 is presented in Figure 2. The predominant peak 1 was identified as neophytadiene. It was the major constituent accounting for about $26 \%$ of the amount of all components. No significant quantitative variation in the neophytadiene content of the cultivars was found. For that reason it was not included in PRM processing. In contrast, the other essential oil components exhibited important qualitative and quantitative variations between the cultivars.

\section{Pattern recognition methods}

The comparison of the HPLC profiles of polyphenols revealed distinct differences of the cultivars examined between them and with the standard Virginia variety K 326 (Figure 4). Similar results were obtained upon processing the CGC profiles of neutral volatiles of essential oils (Figure 4). The ranking of the cultivars by $I_{\mathrm{s}}$ is compatible with the ranking according to the color score and aroma score (Figures 3 and 4).
As judged from both PRM and sensory evaluation, the cultivar Virginia 330 was the most close to the standard, $I_{\mathrm{s}}$ were $97 \%$ (polyphenols) and 95\% (essential oils). The color score for this cultivar was 15.0 and the aroma score was 16.6 against 16.2 (color) and 18.6 (aroma) for the standard (Figures 3 and 4). On the basis of the above data Virginia 330 can be qualified as typical full-flavored aromatic Virginia cultivar. Less similar to the standard is Virginia 0454, assessed as typical full-flavored but less aromatic Virginia. The most distant from the standard is Virginia 42 with an $I_{\mathrm{s}}$ of $93 \%$ (polyphenols) and $90 \%$ (essential oils), color score 10.0 and aroma score 14.2 (Figures 3 and 4). This cultivar could be referred to as a non-typical (filler-type) Virginia.

\section{DISCUSSION}

For classification of natural products by PRM, standards correlated to sensory quality evaluation are requisite $(6,15)$. To this end the chromatographic patterns underlying the different quality classes are to be determined; moreover, prevailing or specific components in these classes can be discriminated and identified in order to serve as discrete chemical indices for quality parameters (12). In our work the HPLC and CGC profiles of the cultivar K 326 were used as reliable standards. This is justified by the fact that K 326 grown in Bulgarian conditions shows high color and aroma scores; our data are in accordance with the high grade index values of this variety reported by American authors (18). In a future study the contribution of different components of HPLC and CGC profiles to the quality characters and their identification will be performed.

Stringent requirements for accurate PRM processing of chromatographic profiles have to be met, namely availability of a large number of well separated, non-overlapping peaks present in sizeable amount, and good reproducibility of the results $(6,12,15)$.

Headspace vapor CGC profiles are usually surveyed when attempting to estimate aroma in tobacco by PRM $(11,12)$. However, these profiles contained a limited number of measurable components and exhibited variation in both qualitative and quantitative aspects. Thus, they can be used only for distinguishing tobacco types (burley, Virginia, Oriental), but not of cultivars of the same type. The real problem however starts when attempting to assess tobacco quality within a given type. To solve this problem, sophisticated technique has been applied, namely specific instrumental devices (closed loop stripping analyzer), as well as modifications of the columns and of injection approaches (12).

In contrast, the CGC analysis of the neutral volatiles of tobacco provided complex patterns containing a multiplicity of well-defined, sizeable and reproducible peaks (23). The data of CGC profiles of the neutral volatiles and the smoking panel assessment of aroma were analyzed by the Stepwise-Forward multiple regression procedure, and good correlation between these parameters was obtained (23). This allows the authors to assume that neutral volatile profiling could be used with subjective smoking to monitor quality control (23). In this paper however only the possi- 


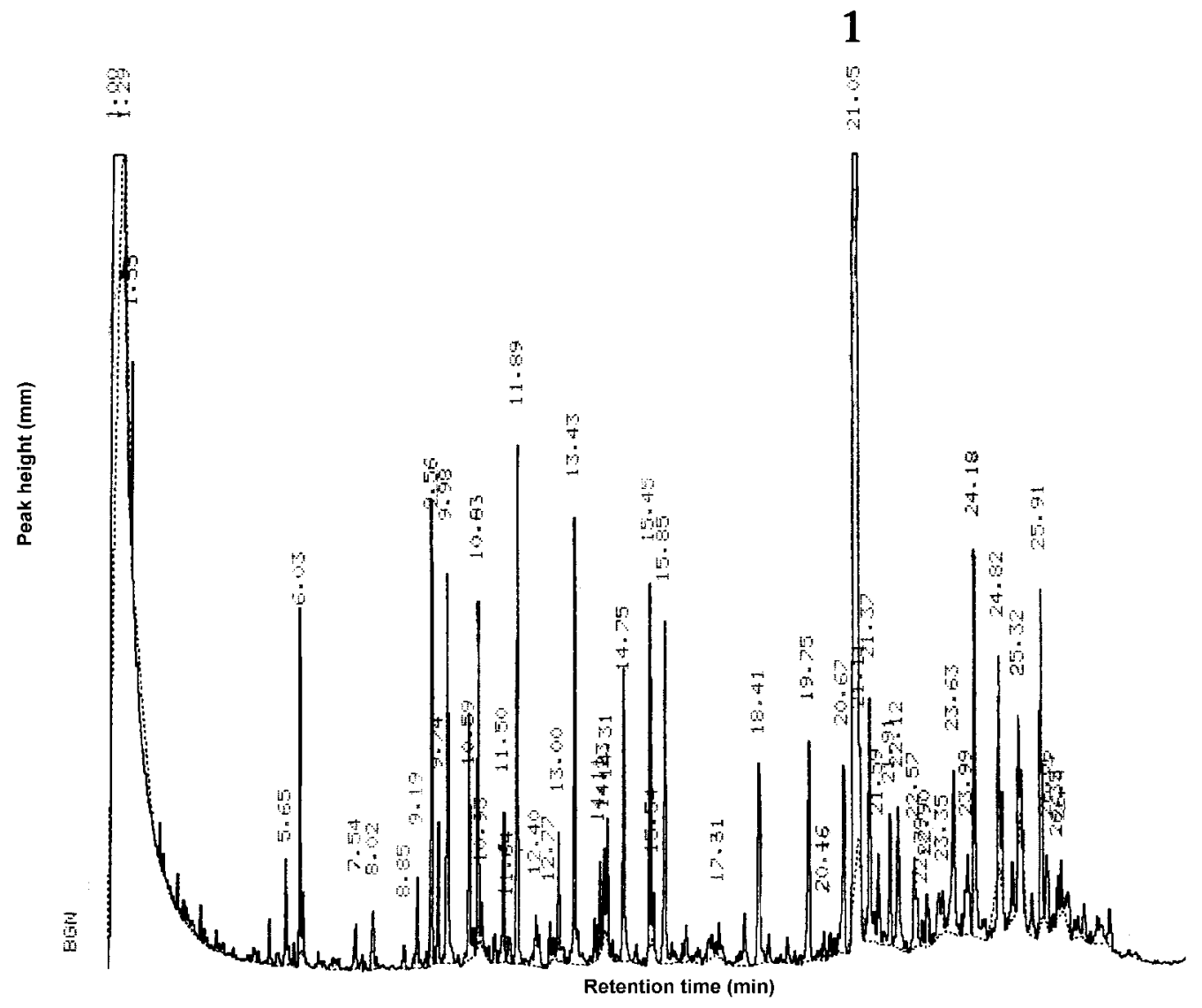

Figure 2. CGC profile of neutral volatiles of essential oils in Virginia variety K 326; component 1 is identified as neophytadiene

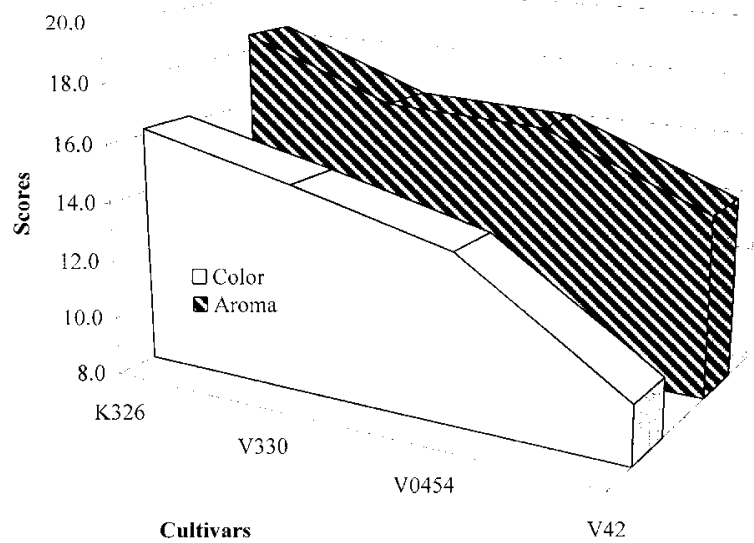

Figure 3. Organoleptic assessments of color and aroma of Virginia tobaccos K 326, Virginia 330 (V330), Virginia 0454 (V0454) and Virginia 42 (V42)

bility to classify tobaccos of different types was demonstrated. In our work, investigating several cultivars belonging to the same type (Virginia), we also used neutral volatiles for CGC and obtained rich and reproducible chromatographic profiles of more than 60 well-defined peaks, constituting a reliable basis for PRM processing. Data of PRM and aroma sensory evaluation were completely compatible and

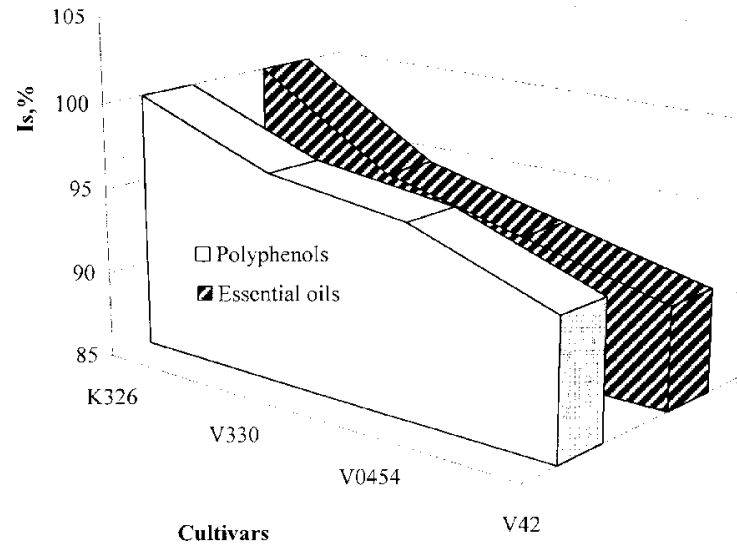

Figure 4. Chemometric evaluation (by PRM) of color and aroma of Virginia tobaccos K 326, Virginia 330 (V330), Virginia 0454 (V0454) and Virginia 42 (V42) using HPLC profiles of polyphenols and CGC profiles of neutral volatiles of essential oils

allowed the classification and ranking of Virginia tobaccos. This forms the basis for recommending the neutral volatile CGC and PRM techniques as simple tools for aroma assessment of tobacco cultivars.

The practice of objective color evaluation of tobacco in- 
volves the use of physicochemical methods, such as reflectance spectrophotometry (8). An alternative objective assessment of color may be based on the relation of polyphenols to color performance; numerous data on the importance of polyphenols for color characteristics are available $(8,9,13$, 19). However, no attempts were made to quantify the relation between polyphenols and color. Our data demonstrated that PRM processing of HPLC profiles of polyphenols can be a reliable means for objective color estimation.

\section{CONCLUSION}

The ranking of Virginia cultivars by sensory evaluation of color and aroma and by the PRM (polyphenol and essential oil profiles) is quite compatible. This finding substantiates the application of PRM as a tool for objective assessment of tobacco quality supplementary to the organoleptic methods. Moreover, PRM enables differentiation between closely related cultivars exhibiting no important variations according to the routine sensory evaluation.

\section{REFERENCES}

1. Bulgarian state standard 8389-85: Tobacco and tobacco products. Evaluation of smoking quality; General Agency of Standardization, Sofia, 1985.

2. Bulgarian state standard 11750-85: Processed and fermented Bulgarian Virginia tobacco; General Agency of Standardization, Sofia, 1985.

3. Cantagrel, R.: Application de l'analyse statistique multidimensionnelle à la différenciation des huiles essentielles de lavandes et de lavandins [Application of statistical multidimensional analysis to the differentiation of essential oils of lavenders (lavandes and lavandins)]; Parfums, Cosmetiques, Aromes 61 (1985) 73-76.

4. Chinchev, B. and B. Stoyanov: Virginia $0454-$ nov ranen I visokodobiven sort tutun [Virginia 0454 - a new early and high yielding tobacco cultivar]; Plant Sci. 23 (7) (1986) 35-39).

5. Court, W.A., J.G. Hendel and R. Poce: Fractionation of flue-cured tobacco samples using Sep-Pak cartridges; Tob. Sci. 35 (1991) 59-62.

6. Dimov, N., A. Tsoutsoulova and E. Stojanov: Pattern recognition methods for discrimination of essential oils (rose oils) by their gas chromatograms; Perfumer \& Flavorist 12 (1987) 45-48.

7. Forina, M. and E. Tiscorina: Pattern recognition methods in the prediction of Italian olive oils by their fatty acid content; Annali di Chimica 72 (1982) 143-146.

8. Garcia, M., P. Barreiro and M. Ruiz-Altisent: Development of a virtual expert for color classification of tobacco leaves. Validation against human experts; in: Sensoral 98 - International Workshop on Sensing Quality of Agricultural Products, Cemagref Editions, Montpellier, France; Actes de Colloque, Technology - Agronomy section, 1, 2000, p. 3086.

9. Grabuloski, T. and Z. Taseska: Study of the correlation between the color of tobacco and the polyphenol content of Prilep tobacco; Tutun (Tobacco) 3-4 (1977) 227-234.

10. Gordon, S.M., J.P. Szidon, B.K. Krotoszynski, R.D. Gibbons and H.J. O'Neill: Volatile organic compounds in exhaled air from patients with lung cancer; Clin. Chem. 31 (1985) 1278-1282.

11. Hasebe, H. and S.Subara: The quality estimation of different tobacco types examined by headspace vapor analysis; Beitr. Tabakforsch. Int. 18 (1999) 213-222.

12. Heinzer, F., H.-P.Maître, M. Rigaux and J. Wild: Pattern recognition of tobacco headspace GC profiles; Beitr. Tabakforsch. Int. 14 (1988) 93-102.

13. Kallianos, A.G.: Phenolics and acids in leaf and their relationship to smoking quality and aroma; Rec. Adv. Tob. Sci. 2 (1976) 61-79.

14. Lloyd, R.A., C.W. Miller, D.L. Roberts, J.A. Giles, J.P. Dickerson, N.H. Nelson, C.E. Rix and P.H. Ayers: Flue-cured tobacco flavor: 1. Essence and essential oil components; Tob. Sci. 20 (1976) 40-48.

15. Massart, L.D., B.G.M. Vandeginste, S.N. Deming, Y. Michotte and L. Kaufman: Chemometrics: a textbook; Elsevier, Amsterdam-Oxford-New York-Tokyo, 1988.

16. Mayfield, H.T., W. Bertsch, T. Mar and J.A. Staroscik: Application of chemometrics to the classification of orange essence oil varieties by GLC; J. High Resolut. Chromatogr. Chromatogr. Commun. 9 (1986) 78-83.

17. Noble, A.C.: Sensory and instrumental evaluation of wine aroma; in: Analysis of foods and beverages, Academic Press Inc., N.Y., 1978, pp. 203-228.

18. Peedin, G.F.: Variety information; in: Flue-cured tobacco information, North Carolina Cooperative Extension Service, North Carolina State University, Raleigh, 1996, pp.10-15.

19. Smeeton, B. and M. Edwards: The influence of genotype and curing on the polyphenol content of fluecured tobacco; Inf. Bull. CORESTA 3 (1993) 80-81.

20. Snook, M.E. and O.T. Chortyk: An improved extraction - HPLC method for tobacco polyphenols; Tob. Sci. 16 (1982) 25-29.

21. Stotesbury, S.J.: A method for the determination of polyphenols in tobacco by HPLC, its application to the analysis of various tobacco types, and to the analysis of smoke; Inf. Bull. CORESTA 3 (1993) 21.

22. Stoyanov, B. and E. Apostolova: Agrobiologichna charakteristika na sorta Virginia 330 [Agrobiological characteristics of the variety Virginia 330]; Bulg. Tobacco 2 (2000) 17-24.

23. Wu, Z., W.W. Weeks and R.C. Long: Contribution of neutral volatiles to flavor intensity of tobacco during smoking; J. Agr. Food Chem. 40 (1992) 1917-1921.

Address for correspondence:

Aglika Edreva

Bulgarian Academy of Sciences

Institute of Genetics

1113 Sofia, Bulgaria 